\title{
Postmastectomy Mammary Reconstruction with the Use of Tissue Expanders Plus Endoprotesis
}

\section{Tamayo Carbon AM1, Vila Garcia E2* and García Torres D ${ }^{3}$}

${ }^{1}$ Specialists of II degree in Plastic Surgery and Caumatology, Surgical Hospital Hermanos Ameijeiras, Cuba

${ }^{2}$ Specialist I Degree in General Surgery, Surgical Hospital Hermanos Ameijeiras, Cuba ${ }^{3}$ Specialists of I degree in Plastic Surgery and Caumatology, Surgical Hospital Hermanos Ameijeiras, Cuba

*Corresponding author: Eyleen Vila Garcia, Assistant Professor, Services of Plastic Surgery and Caumatology and General Surgery, Surgical Hospital Hermanos Ameijeiras, Havana City, Cuba, Tel: 53232327; Email: hielenvg@infomed.sld.cu

\section{Abstract}

Introduction: The reconstruction of the breast after mastectomy is included in the treatment of breast cancer and one of the most used techniques is tissue expansion.

Objective: To evaluate the use of tissue expansion in postmastectomy breast reconstruction.

Material and methods: A descriptive and retrospective study was carried out in the plastic surgery service of Hermanos Ameijeiras Hospital. We included 25 patients from the consultation of oncological deformities of the breast, from January 2016 to August 2018. Tissue expansion consists of expanding the skin and placing a silicone prosthesis. A temporary prosthesis is introduced with a valve, under the muscular plane in a deferred form. In the postoperative period, it will be filled until it reaches the necessary size that allows to place a definitive implant.

Results: $96 \%$ of women were over 30 years of age, $68 \%$ were white and histologically diagnosed with infiltrating ductal carcinoma 60\%. 64\% were reconstructed before the 2 years after the radical mastectomy and in the healthy breast; reductive mastoplasty was performed to achieve symmetry. Complications were present in $20 \%$ of the patients and the results obtained were good in $82.6 \%$ of the patients.

Conclusions: The use of tissue expanders with endoprotesis in postmastectomy breast reconstruction is a safe and effective technique with a high degree of satisfaction for the majority of patients.

Keywords: Postmastectomy mammary reconstruction; Head expanders; Endoprotesis; Breast cancer

\section{Introduction}

Breast cancer (BC) is a significant problem due to the increase in its incidence on a global scale, constituting the second cause of death worldwide. In Cuba, there is a tendency to increase mortality due to this disease, being the first cause of cancer death in women [1-3]. 


\section{International Journal of Transplantation \& Plastic Surgery}

$\mathrm{BC}$ is the most common neoplasm in women [4] and it is estimated that it will affect approximately 1 in every 13 women throughout their lives [5]. Modified radical mastectomy and lumpectomy are the surgical techniques most commonly used for the treatment of BC. The first is extremely mutilating and damages both the body image of the woman and her femininity, with the consequent psychological disorders of anxiety, insomnia, feelings of worthlessness and self-devaluation, as well as personal and interrelated crises; due to the confrontation of the disease and the loss of his breast.

The number of patients who have mastectomy indications for the treatment of BC is still large, but thanks to advances in science and technology, more and more conservative procedures are being done. Fortunately, the techniques that were so mutilating (Halsted Technique), have been replaced by more conservative ones demonstrating the same effectiveness (Madden Technique) [6].

In the last two decades, the reconstruction of the breast has increased, currently existing immediate and late postmastectomy mammary reconstruction techniques such as: cutaneous muscle flap of Dorsal Ancho associated with prosthesis or not, musclecutaneous flap TRAMS (pedunculated or free), microvascular flaps as that of the gluteus maximus muscle and much more recent flaps of perforating arteries [7].

Mammary endoprostheses associated with tissue expansion have been used. This technique was the best option both in its immediate and deferred use. However, the subcutaneous location of the stent resulted in complications such as redundant skin, evidence of the implant, tissue necrosis, implant exposure, capsular contracture and local coldness. These complications decreased with the subpectoral-subserrat placement of the same, achieving the integral rehabilitation of these patients [8-10].

The process of tissue expansion can be defined as the ability of living tissue to increase its surface area in response to the pressure exerted by a growing mass and is based on the principle that soft tissue usually responds to internal and external forces to change its shape and size, regardless of age.

The implantation of a tissue expander is a process that involves a careful analysis of multiple factors before the surgical procedure. There are two indications for reconstruction by tissue expanders. The first is that the quantity and quality of the tissue adjacent to the defect are adequate and the second that the defect of the donor site when creating the flap without expansion is not very significant $[9,11]$.

Soft tissue expansion offers many advantages. It allows a controlled increase of specific tissues, conserves its vascularity improving the blood supply and therefore the viability and prognosis of flaps; generates enough tissue to cover the primary defect, as well as the donor site and being tissue next to the primary defect, it allows to preserve its same texture, color, annexes and sensitivity characteristics. In addition, the operative, inpatient and postoperative recovery times are minimal in comparison with the procedures of myocutaneous or free flaps [12].

In order to evaluate the surgical results of the tissue expansion technique in postmastectomy breast reconstruction at the "Hermanos Ameijeiras" Hospital, the motivation for the development of the current research emerged.

\section{Material and Method}

A descriptive and retrospective study was carried out in patients referred by the multidisciplinary group of Mastology for reconstruction and who attended the outpatient clinic of plastic surgery of the Hospital "Hermanos Ameijeiras", with absence of unilateral or bilateral breast due to radical mastectomy. The study was carried out from January 2016 to August 2018, where a deferred breast reconstruction technique was applied with the use of tissue expansion plus microtextured silicone round mammary endoprosthesis from 300 to 500 $\mathrm{ml}$. The results were evaluated, as well as the possible complications derived from this procedure during a follow-up period of up to one year.

\section{First Surgical Intervention (delayed reconstruction). Marking}

The pocket for the implant is marked $2 \mathrm{~cm}$ below the contralateral submammary groove, at the level of the second rib, the anterior axillary line and the parasternal line. Selection of the volume of the expansive prosthesis to be used, depending on the characteristics and size of the contralateral breast.

\section{Tissue Expansion with Breast Implant. Deferred surgical act: 1st time}

The lateral portion of the scar of the mastectomy is resected. Dissection to the pectoralis major muscle, its lateral fibers are separated. The dissection extends below the myofacial layer, bluntly (with the index finger). The dissection is continued with blunt-tipped scissors to 


\section{International Journal of Transplantation \& Plastic Surgery}

include in the myofascial flap as well as the pectoralis major muscle, the serratus, the external oblique fasciae and the rectus abdominis.

The prosthesis is placed in the submiofascial space and the valve is positioned lateral to the breast and at the subcutaneous level or left external. The drainage is placed under the prosthesis. Suture of the margins of the pectoralis major muscle. Close the skin by planes. A quantity of liquid is instilled through the valve to ensure that it works, depending on the total volume of the expander, between $10 \%$ and $20 \%$ of the total volume.

\section{Postoperative Care for the 1st Time}

Parenteral hydration with 5\% dextrose. Dipirona 600 mg IM every $8 \mathrm{~h}$. Gravinol $50 \mathrm{mg} 1 \mathrm{amp}$ IM if vomiting. Cefazolin $1 \mathrm{~g} \mathrm{EV}$ at 8 hours after surgery. Monitor bleeding by drains. Monitoring of the flap every 2 hours (coloration, capillary fill and temperature). After 24 hours of surgery, a dry cure is made with local antiseptic and the drainage collection is measured. The drainage is removed when the collection is less than $10 \mathrm{ml}$ in $24 \mathrm{~h}$. She is discharged on the 2nd day of surgery if there are no complications. The stitches are removed after 15 days.

\section{Postoperative Care Specific to the 1st Time}

After (2-3 weeks), if the wound healing progresses satisfactorily, the tissue expander is gradually inflated at a rate of approximately $100 \mathrm{cc}$ per week. The expander is filled with an excess of 200 cc above the estimated volume of the opposite breast, checked at 3 months and around 6 months the change is made, so that the tissues are accommodated to their expanded position, and around 6 months the change is made.

\section{Pre-operative Assessment 2nd time}

The patient is evaluated comprehensively to determine what type of intervention should be performed in the contralateral breast: Reduction, pexia or increase.

\section{2nd Definitive Surgical Time}

The expander is removed and replaced by a permanent silicone breast implant of the appropriate size to achieve symmetry with the opposite breast. If the contralateral breast is too large, too small or too small, it may be necessary to reduce it, increase it or raise it respectively, while reconstructing the other to achieve symmetry.

\section{Postoperative Care of the $2^{\text {nd }}$ Time}

Parenteral hydration with 5\% dextrose. Dipirona 600 mg IM every 8h. Gravinol $50 \mathrm{mg} 1 \mathrm{amp}$ IM if vomiting. Cefazolin $1 \mathrm{~g} \mathrm{EV}$ at 8 hours after surgery. Monitor bleeding by drains. Monitoring of the flap every 2 hours (coloration, capillary fill and temperature).

After 24 hours of surgery, a dry cure is made with local antiseptic and the drainage collection is measured. The drainage is removed when the collection is less than 10 $\mathrm{ml}$ in $24 \mathrm{~h}$. The patient was discharged on the second day after surgery if there were no complications. Follow-up by external consultation was done weekly until the month of surgery and then every month until the year of surgery. When complications occurred, they were treated and followed according to their magnitude.
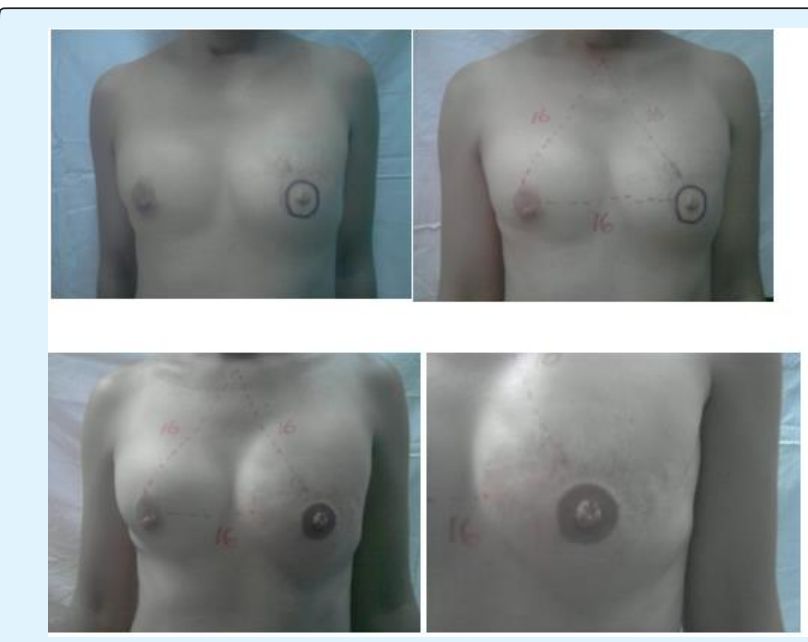

Figure 1: After placement of tissue expander, contralateral autologous nipple graft and areola tattoo is performed.

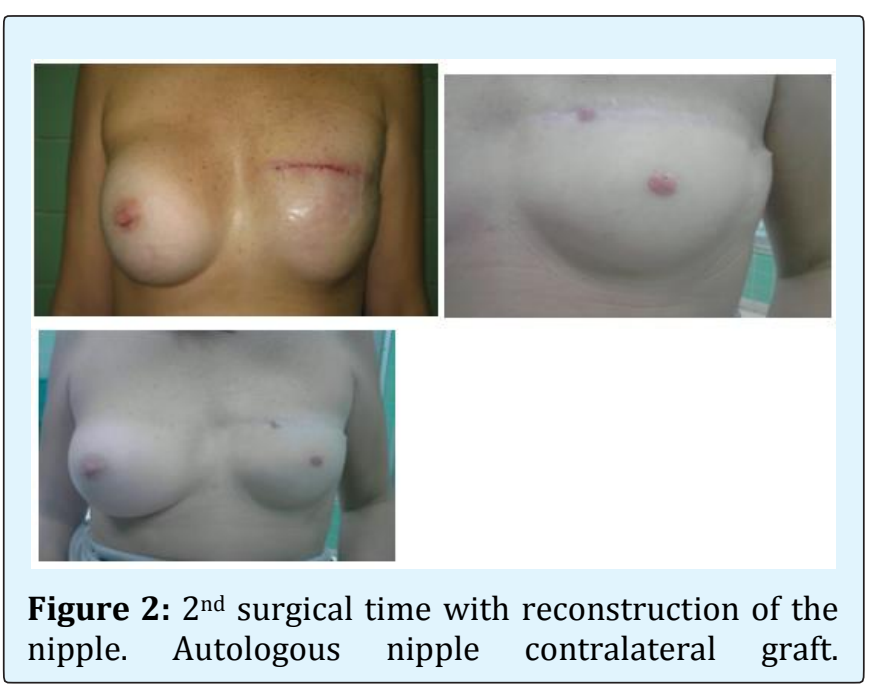




\section{International Journal of Transplantation \& Plastic Surgery}

\section{Results}

Out of a total of 25 women, 23 received modified radical mastectomy and 2 subcutaneous mastectomies. Women aged between 31-45 years prevailed with $96.0 \%$ and there was only one patient under 30 years of age. No patient was found in the group of 46-60 years.

White women predominated $(n=17)$, followed by skin brunette ( $\mathrm{n}=7$ ) and only one black patient. Most of the patients were reconstructed in a shorter time two years postmastectomy $(n=16)$. Only 2 patients had a time greater than 5 years.

The majority of women received chemotherapy as adjuvant treatment $(92.0 \%)$, followed by hormone therapy $(28.0 \%)$ and radiotherapy (8.0\%). Only one patient did not receive adjuvant treatment.

The treatment of the contralateral breast that predominated was reductive mastoplasty (36.0\%), followed by subcutaneous mastectomy plus endoprosthesis (20.0\%) and to a lesser degree, mastoplasty of augmentation and mastopexy (both with $16.0 \%)$.

Only three patients received no treatment in the contralateral breast. The predominant histological lesion was infiltrating ductal carcinoma $(60.0 \%)$, followed by infiltrating lobular carcinoma (24.0\%). Ductal carcinoma in situ and apocrine carcinoma were found in one patient, respectively. In two patients, the results of the histological lesion were not found.

There were only complications in 5 patients $(20.0 \%)$, with a predominance of immediate complications $(n=4$, $80.0 \%)$. According to the complication, the great majority was dependent on the receiving area $(n=4)$ and in only one patient was dependent on the prosthesis. On the other hand, most of the complications were minor $(n=3)$.

Twenty-three patients could be contacted, since 2 died before the data collection for this study. In the vast majority of patients, the result of definitive surgical treatment was rated as very good $(n=19,82.6 \%)$, whereas in only three patients was it fair or poor $(17.4 \%)$. Likewise, most of the women indicated that they were satisfied with the surgical intervention ( $\mathrm{n}=19,82.6 \%)$, while only two $(8.6 \%)$ were unsatisfied.

\section{Discussion}

Currently, breast cancer at young ages associated with a poor prognosis, shows an increasing incidence. This is due mainly to a greater aggressiveness of the disease and its detection in more advanced stages in these age groups, therefore, they exhibit a higher rate of mastectomies, axillary dissection and chemotherapy as adjuvant treatment [1].

Postmastectomy breast reconstruction with tissue expander and / or prosthesis is a reliable procedure with a low rate of complications [13]. The coverage of the cutaneous expander or breast prosthesis is achieved by placing them in the retromuscular space of the pectoralis major; but in this space there is a tension on the device that results in the appearance of a very high breast pole and it is not possible to define a breast groove in anatomical position and shape [14] Some authors choose to disinsert the pectoral muscle, thereby achieving a better breast groove $[15,16]$, but the risk of exposure and extrusion of the expander or prosthesis persists, especially in cases of subcutaneous mastectomy with inferior approach.

Bleicher [17] reported that decision making regarding the performance of the mastectomy was not associated with age, however, younger women (under 40 years old) did show significant differences in relation to their concerns about sexual life after the surgical treatment, the feeling of mutilation and interference with the activities of daily life. This association was also found in other studies $[18,19]$. This explains why young patients are the most frequent group in this study.

In the United States the incidence of breast cancer in white women has maintained a progressive increase since the early 1980s, while in African-American women it has remained stable since the 1990s [11].

In relation to the time elapsed between the mastectomy and the reconstruction, a predominance of patients with time less than two years was found. Some studies have indicated that reconstruction directly after mastectomy is oncologically safe, even in advanced stages. Immediate reconstruction leads to better aesthetic results, reduces anxiety and improves self-esteem and quality of life $[20,21]$.

In the present study, most of the patients received treatment of the contralateral breast, with the main objective of seeking symmetry with the reconstructed breast. This result coincides with other reports that have used both traditional implants and tissue expanders $[11,20,21]$.

In Cuba, in a study conducted by Casadevall, et al. [22] 182 women with modified radical mastectomy were 


\section{International Journal of Transplantation \& Plastic Surgery}

included, infiltrating ductal carcinoma (83.4\%), lobular carcinoma $(8.3 \%)$ and spinal carcinoma $(2.8 \%)$ were the most frequent histological types. In addition, in other studies conducted in Cuba [2], there is a predominance of infiltrating ductal carcinoma. Similar to this investigation.

Scuderi, et al. [23] in a recent inclusion of 242 patients with postmastectomy reconstructive surgery with Becker-type implants, found a global complication rate of $34.2 \%$. The most frequent complication was the poor position of the implant with $13.2 \%$, while severe capsular contracture was detected in 6 cases (2.4\%); Inflation was impossible in 7 cases $(2.8 \%)$ due to valvular obstruction in 3 cases $(1.2 \%)$ and valve displacement in 4 cases $(1.6 \%)$.

Agusti, et al. [24] conducted a study using tissue expanders and found that more than $75 \%$ of the parameters of symmetry between both breasts were rated as good or excellent. The results were rated as excellent in $82 \%$ of the women, while $88 \%$ of the women would choose the same reconstructive procedure.

Cordeiro, et al. [20] reported successful results with the use of tissue expanders in the reconstruction of 315 patients. $88 \%$ of the women showed good to excellent aesthetic results and $95 \%$ of them were satisfied with the reconstruction.

\section{Study Limitations}

- It was performed in a single hospital center.

-The sample is small and does not allow drawing statistically significant conclusions.

\section{Conclusions}

The use of tissue expanders with endoprotesis in postmastectomy mammary reconstruction guarantees the formation of a normal and anatomical looking neomama, preserving the sensitivity of the reconstructed area. It is a safe and effective technique with a high degree of satisfaction for most patients.

\section{References}

1. Comprehensive Program for Cancer Control in Cuba (2010) Guidelines for management. National Cancer Observatory. Havana: National School of Public Health (ENSAP), pp: 19-22.

2. Hernandez J (2004) Adjuvant radiotherapy in the conservative treatment of breast cancer. Lenin Hospital. Rev Havana Med Sciences 9: 480-486.
3. Roa T. Breast General concepts. In: Coiffman F. Text of Surgery.

4. (2015) Statistical health yearbook. Ministry of Public Health. Address of medical records and health statistics. Cuba, Havana.

5. Morales JM, Rodriguez A, Sosa F, Ruiz R (2010) Determination of the psychological impact of immediate breast reconstruction in post-mastectomy patients for breast cancer. Plastic surgery 20(2): 7377.

6. Marti Toro E, Rubio Murillo JM, Sanchez Ponte A, Lopez Ojeda A, Soler nou Juanola Ll, et al. (2012) A challenge in breast reconstruction. Iberlatinamer Plastic Surgery 38: 1-7.

7. Wheat I, Herran FS (2011) Modern breast reconstruction with autologo filling and tisulary expansion. Plastic Surgery 21: 102-110.

8. D'Souza N, Darmanin G, Fedorowicz Z (2011) Immediate versus delayedre construction following surgery for breast cancer. Cochrane Database Syst Rev (7): CD008674.

9. Mangano A (2011) No differences in aesthetic outcome or patient satisfaction between anatomically shaped and round expandable implants in bilateral breast reconstructions: a randomized study the role of the sample size calculation. J Plast Reconstr Surg 128(2): 593.

10. Hsieh F, Shah A, Malata CM (2010) Experience with the Mentor Contour Profile Becker-35 expandable implant in reconstructive breast surgery. J Plast Reconstr Surg 63: 1124-1130.

11. Lund MJ, Trivers KF, Porter PL, Coates RJ, LeylandJones B, et al. (2009) Race and triple negative threats to breast cancer survival: a population-based study in Atlanta, GA. Breast Cancer Res Treat 113(2): 357-370.

12. Gahm J, Edsander-Nord A, Jurell G, Wickman M (2010) No differences in aesthetic outcome or patient satisfaction between anatomically shaped and round expandable implants in bilateral breast reconstructions: a randomized study. J Plast Reconstr Surg 126: 1419-1427.

13. Gutierrez Gomez C, Rivas Leon B, Cardenas Mejia (2012) A Breast reconstruction with tissue expander and implant. Indications and experience in 24 cases. Plast Surg Iberolatinoam 38(4): 323-328. 


\section{International Journal of Transplantation \& Plastic Surgery}

14. Davalos-Davalos P, Ramirez-Rivera JI, DavalosDavalos PA (2015) Pectoralis major and external oblique flaps for coverage of expanders and/or implants in postmastectomy reconstruction. Cir. plást. Iberolatinoam 41(1): 33-39.

15. Serra JM, Fontdevila J, Monner J, Benito J (2004) Mammary reconstruction using tissue expander and partial detachment of the pectoralis major muscle to expand the lower breast quadrants. Ann Plast Surg 53(4): 317-321.

16. Bernard RW, Boutros S (2005) Subincisional muscular coverage of expander implants in immediate breast reconstruction with pectoralis flaps. Ann Plast Surg 54(4): 352-355.

17. Bleicher RJ, Abrahamse P, Hawley ST, Katz SJ, Morrow M (2008) The Influence of Age on the Breast Surgery Decision-Making Process. Ann Surg Oncol 15(3): 854862.

18. Dobi A, Kelemen G, Kaizer L, Weiczner R, Thurzó L, et al. (2011) Breast cancer under 40 years of age: increasing number and worse prognosis. Pathol Oncol Res 17: 425-428.

19. Miles RC, Gullerud RE, Lohse CM, Jakub JW, Degnim $\mathrm{AC}$, et al. (2012) Local Recurrence after BreastConserving Surgery: Multivariable Analysis of Risk Factors and the Impact of Young Age. Ann Surg Oncol 19: 1153-1159.

20. Cordeiro PG, Pusic AL, Disa JJ, McCormick B, VanZee K (2004) Irradiation after immediate tissue expander/implant breast reconstruction: outcomes, complications, aesthetic results, and satisfaction among 156 patients. Plastic Reconstr Surg 113(3): 877-881.
21. Eriksen C, Frisell J, Wickman M, Lidbrink E, Krawiec $\mathrm{K}$, et al. (2011) Immediate reconstruction with implants in women with invasive breast cancer does not affect oncological safety in a matched cohort study. Breast Cancer Res Treat 127(2): 439-446.

22. Casadevall I, Villavicencio P, Castillo IM, Rojas MI, Castañeda MA (2008) Cosmetic surgery and modified radical mastectomy in stage I and II breast cancer. Cuban Magazine of Surgery 47(2).

23. Scuderi N, Alfano C, Vittorio G, Rubino C, Chiummariello S, Puddu A, et al. (2011) Multicenter Study on Breast Reconstruction Outcome Using Becker Implants. Aesth Plast Surg 35(1): 66-72.

24. Agusti A, Ward A, Montgomery C, Mohammed K, Gui GP (2016) Aesthetic and oncologic outcomes after one-stage immediate breast reconstruction using a permanent biodimensional expandable implant. J Plast Reconstr Aesthet Surg 69(2): 211-220.

25. Salgarello M, Barone, Adesi L, Terribile D, Masetti R (2011) Update on one stage immediate breast reconstruction with definitive prosthesis after sparing mastectomies. Breast 20(1): 7-14.

26. Salgarello M, Visconti G, Barone Adesi L, Franceschini G, Masetti R (2015) Contralateral breast symmetrisation in immediate prosthetic breast reconstruction after unilateral nipple sparing mastectomy: the tailored reduction/augmentation mammaplasty. Arch Plast Surg 42(3): 302-308.

27. Salgarello M, Visconti G, Barone Adesi L, Franceschini G, Magno S, et al. (2012) Inverted T skin reducing mastectomy with immediate implant reconstruction using the submuscular subfascial pocket. Plast Reconstr Surg 130(1): 31-41. 